\title{
Reply
}

\section{Should a priori analogies be regarded as deductive arguments?}

\section{Trudy Govier}

In his recent essay "Classifying and Analyzing Analogies," (Informal Logic 21.3, Autumn 2001, pp. 199-218), Bruce Waller supports my distinction between $a$ priori and inductive analogies but argues that I am mistaken in my claim that $a$ priori analogies are not deductive arguments. While Waller offers an important discussion for which I am grateful, I believe that his case is flawed due to his failure to distinguish between an argument per se, as articulated by its author, and a philosophical reconstruction of that argument.

What I call a priori analogies (Govier, 1999) Wisdom (1957) called case-bycase reasoning and Bickenbach (1977) called reflective reasoning. Waller claims that such arguments are deductive and have the following form:

1. We both agree with case a.

2. The most plausible reason for believing a is the acceptance of principle $\mathrm{C}$,

3. $\mathrm{C}$ implies $\mathrm{b}$ ( $\mathrm{b}$ is a case that fits under principle $\mathrm{C}$ ).

Therefore:

4. Consistency requires the acceptance of $\mathrm{b}$.

However 'premises' (2) and (3) are not explicit in many analogy arguments, as Waller acknowledges. In fact, he acknowledges that framing the general principle, $\mathrm{C}$, is often a difficult and challenging task for those reflecting on the argument. We accept a case (a) and the analogy between (a) and (b) is drawn in the stated argument. We have to think to come up with $\mathrm{C}$, the general principle from which both (a) and (b) are to be inferred. $\mathrm{C}$ is not something ready-made, Waller emphasizes. To come up with $\mathrm{C}$ will require thinking —critical thinking, philosophical thinking, if you like. I would say that such thinking is a priori. Waller and I agree that it is often of great importance and that a priori analogies are useful sorts of arguments because reflection on them will lead us to engage in it.

When we arrive at $\mathrm{C}$, we can recast the original a priori argument as a deductive argument, as Waller suggests. I agree with Waller on this point and said as much in the earlier piece "Analogies and Missing Premises," (Informal Logic, 11, no. 3, Fall 1989, pp. 141-152) which Waller is discussing (reprinted as Govier, 1999). But I disagree on two further points. 
First, to claim, as Waller does, that it is we, as critics and audience, who have to think in order to arrive at the principle $\mathrm{C}$ is, in effect, to acknowledge that $\mathrm{C}$ is not an element in the original analogy. Obviously, if $\mathrm{C}$ were a stated premise offered by the original arguer, we would not have to do all this thinking to come up with it. So it must be that the argument is being represented as deductive because of the addition of an unstated premise alleged to be implicit in the original. If $\mathrm{C}$ is to count as an implicit premise in the original argument, less creativity on the part of the critic should be required in its generation. To qualify as implicit, $\mathrm{C}$ should be more readily extractable from what is given: the wording or context of the argument, or knowledge about what its author believed or intended.

Second, to urge, as Waller does, that it is a "challenge" for the critic or audience to arrive at the principle is in effect to admit that the principle is not a stated or an implicit premise in the original argument. We should say instead that a critical thinker encountering an a priori analogy may arrive at some principle assuming the role of $\mathrm{C}$ after reflection and discussion. He or she may then reconstruct the $a$ priori analogy as a deductive argument along lines similar to what Waller suggests. But this is not to say that the a priori analogy as it was first presented counts as a deductive argument. What is going on? The critic has come up with a reconstruction that is a deductive argument and its accuracy as a rendition of the original may be subject to debate. Clearly Waller is no dogmatic deductivist but it is worth noting that we have arrived back at the old strategy of rendering arguments of contested forms deductive by supplying extra premises.

Or greater interest, I suspect, is the nature of the reasoning in which a critic will engage in such a case. I doubt whether such reasoning can be exhaustively described as deductive, although it seems clear to me, as it does to Waller, that most of it will not be inductive. Suppose we accept a case (a) as described by an arguer and we begin to ask ourselves, as Waller usefully suggests that we do, why we accept (a). Why do we believe what we do? We then begin to propose various principles of the type of $\mathrm{C}$, which we might accept and from which the correctness of (a) might be derived. Clearly, elements of such reasoning would be deductive-finding out what $\mathrm{Cl}$ entails, whether some proposed counter-example to some $\mathrm{C} 1$ would refute it, and so on. But equally clearly, other aspects of this reasoning would not be so. Abductive reasoning may be involved. We accept (a); we ask ourselves for a hypothesis that would explain why we accept (a). Furthermore-and distinct from the suggestion of abduction in our reflections on a proposed $\mathrm{C}$ and its explanatory merits-reasoning about the correct application of words and the correct use of concepts may be involved. For instance, if a principle, $\mathrm{C} 1$ comes forth as a plausible explanatory contender, and $\mathrm{Cl}$ states that all $\mathrm{x}$ are $y$, then to determine whether putatiave instance of an $x$ that is not a $y$ counts as a counter-example to $\mathrm{Cl}$, we have to reflect on whether that instance genuinely counts as $\mathrm{x}$. (Wisdom, 1957, emphasized this sort of point.) 
The question of how we reason when we ask ourselves what general principles we accept seems to me to be of deep interest, and Waller does us a service in bringing it to our attention in the context of a priori analogies. But I find the distinction between a priori and deductive crucial at this point. It strikes me as entirely plausible to say that such reasoning will be (mostly) a priori-but quite implausible to say that it is deductive.

\section{References}

Bickebach, Jerome. (1977). The nature and scope of reflective reasoning. Ph.D. Thesis. Edmonton: University of Alberta

Govier, Trudy. (1999). "Euclid's Disease and Desperate Violinists: Do Analogies Have Missing Premises?" In Trudy Govier, The Philosophy of Argument, pp.137-153. Newport News, VA: Vale Press.

Wisdom, John. (1957). Explanation and proof. Lectures at the University of Virginia. Unpublished manuscript. 